\title{
Validation of Open-Heart Intraoperative Risk score to predict a prolonged intensive care unit stay for adult patients undergoing cardiac surgery with cardiopulmonary bypass
}

This article was published in the following Dove Press journal:

Therapeutics and Clinical Risk Management

\author{
Sirirat Tribuddharat ${ }^{\prime}$ \\ Thepakorn \\ Sathitkarnmanee ${ }^{1}$ \\ Kriangsak \\ Ngamsaengsirisup' \\ Chawalit Wongbuddha ${ }^{2}$ \\ 'Department of Anesthesiology, \\ ${ }^{2}$ Division of Cardiothoracic Surgery, \\ Department of Surgery, Faculty of \\ Medicine, Khon Kaen University, \\ Khon Kaen, Thailand
}

Background: A prolonged stay in an intensive care unit (ICU) after cardiac surgery with cardiopulmonary bypass (CPB) increases the cost of care as well as morbidity and mortality. Several predictive models aim at identifying patients at risk of prolonged ICU stay after cardiac surgery with $\mathrm{CPB}$, but almost all of them involve a preoperative assessment for proper resource management, while one - the Open-Heart Intraoperative Risk (OHIR) score - focuses on intraoperative manipulatable risk factors for improving anesthetic care and patient outcome.

Objective: We aimed to revalidate the OHIR score in a different context.

Materials and methods: The ability of the OHIR score to predict a prolonged ICU stay was assessed in 123 adults undergoing cardiac surgery (both coronary bypass graft and valvular surgery) with CPB at two tertiary university hospitals between January 2013 and December 2014. The criteria for a prolonged ICU stay matched a previous study (ie, a stay longer than the median).

Results: The area under the receiver operating characteristic curve of the OHIR score to predict a prolonged ICU stay was 0.95 (95\% confidence interval $0.90-1.00)$. The respective sensitivity, specificity, positive predictive value, and accuracy of an OHIR score of $\geq 3$ to discriminate a prolonged ICU stay was $93.10 \%, 98.46 \%, 98.18 \%$, and $95.9 \%$.

Conclusion: The OHIR score is highly predictive of a prolonged ICU stay among intraoperative patients undergoing cardiac surgery with CPB. The OHIR comprises of six risk factors, five of which are manipulatable intraoperatively. The OHIR can be used to identify patients at risk as well as to improve the outcome of those patients.

Keywords: predictive models, validation studies, cardiac surgical procedures, cardiopulmonary bypass, intensive care units, OHIR score

\section{Introduction}

A prolonged stay in an intensive care unit (ICU) after cardiac surgery with cardiopulmonary bypass (CPB) increases not only the overall cost of care but also patient morbidity and mortality. ${ }^{1}$ Being able to predict which patients might have a tendency for a prolonged ICU stay would help with patient and resource management. ${ }^{2}$

There are several predictive models for identifying patients at risk of prolonged ICU stay after cardiac surgery with $\mathrm{CPB},{ }^{3-6}$ but almost all of them involve a preoperative assessment for proper resource management. One model - the Open-Heart Intraoperative Risk (OHIR) score - considers intraoperative, manipulatable risk factors for improving anesthetic care and patient outcome. ${ }^{7}$ The OHIR model comprises six risk factors: age ( $\geq 60$ years), $\mathrm{P}_{\mathrm{a}} \mathrm{O}_{2} /$ $\mathrm{F}_{\mathrm{i}} \mathrm{O}_{2}(\mathrm{P} / \mathrm{F})$ ratio $(\leq 200 \mathrm{mmHg})$, platelet count $\left(\leq 120,000 / \mathrm{mm}^{3}\right)$, inotrope/vasopressor
Correspondence: Thepakorn

Sathitkarnmanee

Department of Anesthesiology, Faculty of Medicine, Khon Kaen University,

I23 Mitrapap Road, Khon Kaen 40002, Thailand

Tel +66819547622

Email thepakorns@gmail.com 
Table I OHIR score model for predicting prolonged ICU stay

\begin{tabular}{lll}
\hline Risk factors & \multicolumn{2}{l}{ Score } \\
\cline { 2 - 3 } & Present & Absent \\
\hline Age $(\geq 60$ years) & $\mathrm{I}$ & 0 \\
P/F ratio $(\leq 200 \mathrm{mmHg})$ & $\mathrm{I}$ & 0 \\
Platelet count $\left(\leq 120,000 / \mathrm{mm}^{3}\right)$ & $\mathrm{I}$ & 0 \\
Inotrope/vasopressor requirement $(\geq 2$ drugs) & 2 & 0 \\
Serum potassium $(\leq 3.2 \mathrm{mEq} / \mathrm{L})$ & $\mathrm{I}$ & 0 \\
$\mathrm{AF}^{\mathrm{a}}$ (grading $\left.\geq 2\right)$ & $\mathrm{I}$ & 0
\end{tabular}

Notes: $\mathrm{OHIR}$ score, total score $=7$; score $\geq 3$ suggests a prolonged stay in ICU. ${ }^{\mathrm{a} A F}$ grade $0=$ no $A F, A F$ grade $I=$ mild degree/need no therapy, AF grade $2=$ moderate degree/need drug therapy, and AF grade $3=$ severe degree/refractory to drug therapy. Abbreviations: ICU, intensive care unit; OHIR, Open-Heart Intraoperative Risk; $\mathrm{P} / \mathrm{F}, \mathrm{P}_{\mathrm{a}} \mathrm{O}_{2} / \mathrm{F}_{\mathrm{i}} \mathrm{O}_{2} ; \mathrm{AF}$, atrial fibrillation.

requirement ( $\geq 2$ drugs), serum potassium $(\leq 3.2 \mathrm{mEq} / \mathrm{L})$, and atrial fibrillation (grading $\geq 2$; Table 1). Five factors in the model can be managed intraoperatively. OHIR has a score of 7; a score of $\geq 3$ indicates a prolonged ICU stay is likely. This scoring model has not been reassessed among different patients with the same type of surgery, hence our objective.

\section{Materials and methods}

This was a retrospective, observational, and analytical study. The protocol was approved by the Khon Kaen University Ethics Committee in Human Research (HE581287), with a waiver for requiring informed consent from the patient since confidentiality protection was warranted. The data extracting sheets did not include the name of the patient, and so a unique, masked study number was used instead. This study was registered with ClinicalTrial.gov (NCT02945358).

The inclusion criteria were patients between 18 and 75 years of age undergoing cardiac surgery - ie, both coronary bypass graft and valvular that included the use of $\mathrm{CPB}$. The exclusion criteria were patients undergoing emergency surgery or patients receiving special devices such as intra-aortic balloon pump or extracorporeal membrane oxygenation.

Standard anesthetic and surgical techniques for openheart surgery with $\mathrm{CPB}$ were used. Transfusion criteria included the following: hemoglobin level $<8 \mathrm{~g} / \mathrm{dL}$, platelet number $<50,000 / \mathrm{mm}^{3}$, or clinical coagulopathy. Crystalloid and colloid were used to maintain a central venous pressure of between 8 and $12 \mathrm{mmHg}$ or a pulmonary arterial pressure of between 12 and $15 \mathrm{mmHg}$. Catecholamine infusions were used to support hemodynamic stability (dobutamine then epinephrine or norepinephrine).

Postsurgery, the patients were transferred to ICU where they received ventilator support. Patients were weaned off the ventilator and extubated when and if they were awake; had satisfactory ventilation and oxygenation (ie, on $\mathrm{FiO}_{2} \leq 40 \%$ with $\mathrm{P}_{\mathrm{a}} \mathrm{O}_{2}>60 \mathrm{mmHg}, \mathrm{P}_{\mathrm{a}} \mathrm{CO}_{2}>30$ and $<50 \mathrm{mmHg}$, and $\mathrm{pH}>7.30$, or $\mathrm{SpO}_{2}>92 \%$ ); and had hemodynamic stability.
The criteria for discharging patients from the ICU to the cardiovascular ward were as follows: alert and cooperative, respiratory rate $<25 / \mathrm{min}$ without assistance from mechanical ventilation, $\mathrm{P}_{\mathrm{a}} \mathrm{O}_{2}>80 \mathrm{mmHg}$ and $\mathrm{P}_{\mathrm{a}} \mathrm{CO}_{2}<45 \mathrm{mmHg}$, hemodynamically stable, and adequate analgesia.

We reviewed all eligible medical records at Srinagarind Hospital and Queen Sirikit Heart Center of the Northeast, Khon Kaen University, between January 2013 and December 2014. The extracted data comprised patient clinical data and all risk factors in the OHIR score at 3 hours after CPB. We applied the OHIR scoring (Table 1) to our data to assess its performance. We used the same criteria for a prolonged ICU stay as our previous study (namely, a stay longer than the median). ${ }^{7}$

\section{Statistical analyses}

The discrimination ability of the OHIR score to predict a prolonged ICU stay was assessed by evaluating the area under the receiver operating characteristic curve (AUC for ROC). We also determined the sensitivity and specificity, positive and negative predictive values, accuracy, and positive likelihood ratio. Statistical analyses were performed using SPSS for Windows version 16.0 (SPSS Inc., Chicago, IL, USA).

\section{Results}

A total of 123 cases were recruited. The median ICU stay was 42 (interquartile range 40-62) hours. Fifty-eight cases were classified as being a prolonged ICU stay. The group having a prolonged ICU stay had a higher age, New York Heart Association class, American Society of Anesthesiologists classification, and more comorbidities. The demographic and clinical data of the patients are listed in Table 2.

Patients with an OHIR score between 0 and 2 had a shorter ICU stay than those with a score between 3 and 6 . Table 3 lists the mean ICU stay for each OHIR score.

The AUC for ROC of the OHIR score for segregating prolonged ICU stay among our patients yielded a nearly perfect classification of 0.95 (95\% confidence interval 0.90-1.00; Figure 1). A cutoff of $\geq 3$ of the OHIR score yielded the maximum sensitivity and specificity (Figure 2).

The OHIR score had a very high sensitivity, specificity, positive predictive value, and accuracy. Table 4 lists the sensitivity, specificity, positive predictive value, negative predictive value, accuracy, positive likelihood ratio, and AUC for ROC of OHIR score $\geq 3$ for discriminating a prolonged ICU stay.

\section{Discussion}

To identify patients at risk of a prolonged ICU stay, several predictive models have been proposed and used. 
Table 2 Demographic and clinical data

\begin{tabular}{|c|c|c|c|c|}
\hline Characteristics & $\begin{array}{l}\text { Total } \\
(n=123)\end{array}$ & $\begin{array}{l}\text { Prolonged ICU } \\
(\mathrm{n}=58)\end{array}$ & $\begin{array}{l}\text { Nonprolonged ICU } \\
(n=65)\end{array}$ & $P$-value \\
\hline Age (years) & $56.67 \pm 12.34$ & $61.97 \pm 10.42$ & $51.94 \pm 12.07$ & $<0.001$ \\
\hline BMI $\left(\mathrm{kg} / \mathrm{m}^{2}\right)$ & $22.94 \pm 4.80$ & $22.68 \pm 4.46$ & $23.16 \pm 5.09$ & 0.584 \\
\hline \multicolumn{5}{|l|}{ Gender } \\
\hline Male & 67 (54.47\%) & 35 (60.34\%) & 32 (49.23\%) & 0.217 \\
\hline \multicolumn{5}{|l|}{ Type of operation } \\
\hline CABG & 43 & 24 & 19 & 0.158 \\
\hline Valve surgery & 70 & 26 & 44 & 0.011 \\
\hline CABG + valve surgery & 10 & 8 & 2 & 0.029 \\
\hline \multicolumn{5}{|l|}{ NYHA class } \\
\hline I-II & 102 & 41 & 61 & \multirow[t]{2}{*}{$<0.001$} \\
\hline III-IV & 21 & 17 & 4 & \\
\hline \multicolumn{5}{|l|}{ ASA classification } \\
\hline $1-2$ & 85 & 31 & 54 & \multirow[t]{2}{*}{$<0.001$} \\
\hline $3-5$ & 38 & 27 & $\mathrm{II}$ & \\
\hline Ejection fraction & $55.36 \pm 14.69$ & $52.61 \pm 15.77$ & $57.70 \pm 13.39$ & 0.062 \\
\hline \multicolumn{5}{|l|}{ Preoperative variables } \\
\hline Hypertension & & 35 & 17 & $<0.001$ \\
\hline Diabetes mellitus & & 24 & 15 & 0.029 \\
\hline Myocardial infarction & & 10 & 7 & 0.299 \\
\hline Dyslipidemia & & 22 & 18 & 0.226 \\
\hline Atrial fibrillation & & 18 & 25 & 0.388 \\
\hline Congestive heart failure & & 13 & 4 & 0.009 \\
\hline Kidney impairment/failure & & 12 & 4 & 0.017 \\
\hline Creatinine value $(\mathrm{mg} / \mathrm{mL})$ & $1.05 \pm 0.53$ & $1.24 \pm 0.68$ & $0.88 \pm 0.25$ & $<0.001$ \\
\hline CPB time (minutes) & $145.29 \pm 74.43$ & $159.90 \pm 92.73$ & $132.26 \pm 50.35$ & 0.039 \\
\hline Aortic cross-clamp time (minutes) & $95.93 \pm 38.46$ & $101.05 \pm 39.53$ & $91.35 \pm 39.14$ & 0.175 \\
\hline Mechanical ventilation (hours) & $|8.75 \pm 37.0|$ & $29.75 \pm 51.50$ & $9.11 \pm 8.12$ & 0.004 \\
\hline Endotracheal tube retaining (hours) & $19.01 \pm 36.99$ & $29.96 \pm 51.45$ & $9.40 \pm 8.36$ & 0.004 \\
\hline \multirow[t]{2}{*}{ OHIR score } & $2(2-3)$ & $3(3-4)$ & $2(I-2)$ & \multirow[t]{2}{*}{$<0.001$} \\
\hline & $2.50 \pm 1.28$ & $3.5 \pm 1.06$ & $1.6 \pm 0.63$ & \\
\hline \multirow[t]{2}{*}{ ICU stay (hours) } & $42(40-62)$ & $63(45-88)$ & $40(3|-4|)$ & \multirow[t]{2}{*}{$<0.001$} \\
\hline & $58.58 \pm 5.08$ & $84.57 \pm 64.27$ & $35.38 \pm 8.94$ & \\
\hline \multirow[t]{2}{*}{ Hospital stay (days) } & $14(\mid 1-20)$ & $14(10-23)$ & $15(11-20)$ & \multirow[t]{2}{*}{0.100} \\
\hline & $17.18 \pm 9.62$ & $|8.82 \pm| 2.7 \mid$ & $15.77 \pm 5.50$ & \\
\hline
\end{tabular}

Note: Values are presented as mean \pm SD, number (\%), or median (IQ range).

Abbreviations: ICU, intensive care unit; BMI, body surface area; CABG, coronary artery bypass graph; NYHA, New York Heart Association; ASA, American Society of Anesthesiologists; CPB, cardiopulmonary bypass; OHIR, Open-Heart Intraoperative Risk; SD, standard deviation.

The EuroSCORE was initially constructed for the prediction of early mortality among cardiac patients in Europe,,${ }^{8,9}$ but was later validated as a predictive tool for estimating patient risk in terms of ICU stay. ${ }^{10}$ The reported common risk factors

Table 3 Number of patients and mean ICU stay for each OHIR score

\begin{tabular}{lll}
\hline OHIR score & Number of patients & ICU stay (hours) \\
\hline 0 & 6 & $44.3 \pm 15.90$ \\
1 & 19 & $35.2 \pm 9.02$ \\
2 & 43 & $38.5 \pm 19.18$ \\
3 & 27 & $62.7 \pm 19.91$ \\
4 & 21 & $95.4 \pm 73.06$ \\
5 & 5 & $119.2 \pm 116.22$ \\
6 & 2 & $161.5 \pm 167.58$ \\
7 & 0 & 0 \\
\hline
\end{tabular}

Note: Values are presented as mean \pm SD.

Abbreviations: ICU, intensive care unit; OHIR, Open-Heart Intraoperative Risk; $\mathrm{SD}$, standard deviation. for prolonged ICU stay include the following: 1) advanced age ( $>65$ years), 2) mean pulmonary artery pressure $(>21 \mathrm{mmHg})$, and 3$)$ decreased $\mathrm{P} / \mathrm{F}$ ratio $(<300 \mathrm{mmHg})$ on admission to ICU. ${ }^{3}$ Another study included the following: 1) body mass index, 2) type of surgery, 3) CPB machine use, 4) use of packed red cells, 5) nonelective surgery, and 6) number of complications. ${ }^{5}$

A 2016 systematic review of 29 articles categorized the predictors of ICU length of stay into 11 patient factors, 19 comorbidity factors, 10 surgical factors, and 6 complication factors. ${ }^{6}$ Most of these risk factors were assessed preoperatively for the purpose of resource management. An OHIR score model, published in 2014, comprised six risk factors: age ( $\geq 60$ years), $\mathrm{P} / \mathrm{F}$ ratio $(\leq 200 \mathrm{mmHg}$ ), platelet count $\left(\leq 120,000 / \mathrm{mm}^{3}\right)$, inotrope/vasopressor requirement ( $\geq 2$ drugs), serum potassium $(\leq 3.2 \mathrm{mEq} / \mathrm{L})$, and atrial fibrillation (grading $\geq 2$ ). ${ }^{7}$ All except one risk factor 


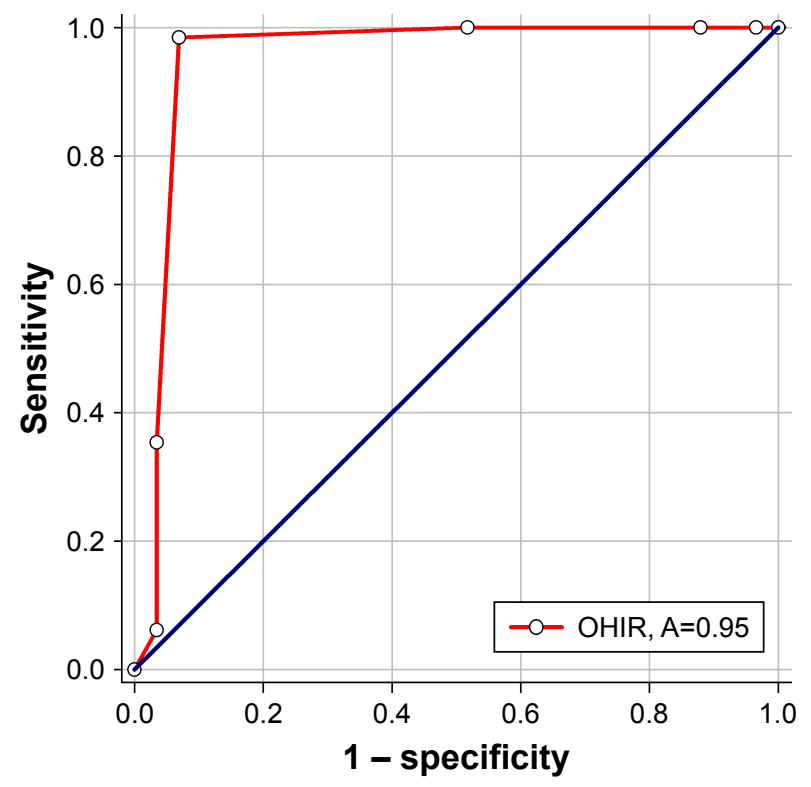

Figure I AUC for ROC of the OHIR score to discriminate a prolonged ICU stay. Abbreviations: OHIR, Open-Heart Intraoperative Risk; A, area; AUC for ROC, area under the receiver operating characteristic curve; ICU, intensive care unit.

(ie, age $\geq 60$ years) are manageable. The model has a total score of 7 , with a score $\geq 3$ suggesting a potentially prolonged ICU stay. The authors claimed that the OHIR score could be used as a guide for managing patients intraoperatively, thereby reducing the score to below 3 so that they would have a lower probability of a prolonged ICU stay.

The median ICU stay in this study was 42 hours, which is the same as our previous study, ${ }^{7}$ suggesting the appropriateness of the statistical criteria for inferential purposes.

Our study confirms that the OHIR score has a very good discriminatory ability for predicting prolonged ICU stay among adult patients undergoing cardiac surgery with CPB.

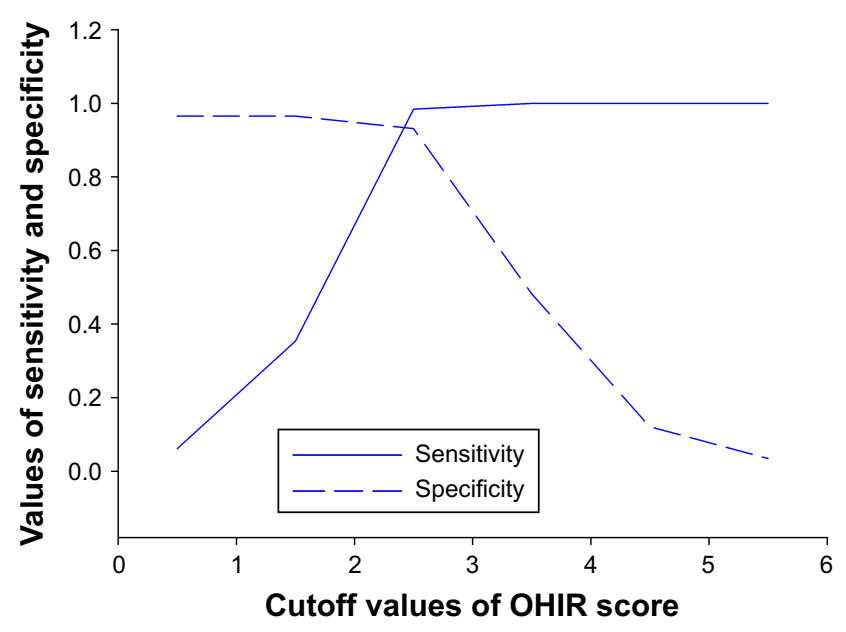

Figure 2 Cutoff point for the OHIR score. Abbreviation: OHIR, Open-Heart Intraoperative Risk.
Table 4 Sensitivity, specificity, positive predictive value, negative predictive value, and AUC for ROC of the OHIR score $\geq 3$

\begin{tabular}{lll}
\hline Parameter & Value & $\mathbf{9 5 \% ~ C l}$ \\
\hline Sensitivity (\%) & 93.10 & $83.27-98.09$ \\
Specificity (\%) & 98.46 & $91.72-99.96$ \\
Positive predictive value (\%) & 98.18 & $88.52-99.74$ \\
Negative predictive value (\%) & 94.12 & $86.13-97.63$ \\
Accuracy (\%) & 95.9 & - \\
Positive likelihood ratio & 60.52 & - \\
AUC for ROC & 0.96 & $0.92-1.00$ \\
\hline
\end{tabular}

Abbreviations: $A \cup C$ for ROC, area under the receiver operating characteristic curve; OHIR, Open-Heart Intraoperative Risk; Cl, confidence interval.

The overall performance of the OHIR score in the current context is better than our original study. This model may be used as a guide for managing patients intraoperatively so as to reduce their OHIR score to below 3, thereby shortening their ICU stay.

\section{Limitations}

Even though the group of patients in this study was different from our previous study, they were from the same setting. Further study to validate this score in different environments is recommended.

\section{Conclusion}

The OHIR score is highly predictive at the intraoperative stage of a prolonged ICU stay among patients undergoing cardiac surgery with $\mathrm{CPB}$. The OHIR comprises six risk factors, with five that are manipulatable intraoperatively. The OHIR can be used to identify patients at risk as well as to improve patient outcomes.

\section{Acknowledgments}

The authors thank Mr Bryan Roderick Hamman for his assistance with the English language presentation of the manuscript under the support of the Publication Clinic, Khon Kaen University, Thailand.

\section{Disclosure}

The authors report no conflicts of interest in this work.

\section{References}

1. Williams TA, Ho KM, Dobb GJ, Finn JC, Knuiman M, Webb SA. Effect of length of stay in intensive care unit on hospital and long-term mortality of critically ill adult patients. Br J Anaesth. 2010;104(4):459-464.

2. Hein OV, Birnbaum J, Wernecke K, England M, Konertz W, Spies C. Prolonged intensive care unit stay in cardiac surgery: risk factors and long-term-survival. Ann Thorac Surg. 2006;81(3):880-885.

3. Nakasuji M, Matsushita M, Asada A. Risk factors for prolonged ICU stay in patients following coronary artery bypass grafting with a long duration of cardiopulmonary bypass. J Anesth. 2005;19(2):118-123. 
4. Gruenberg DA, Shelton W, Rose SL, Rutter AE, Socaris S, McGee G. Factors influencing length of stay in the intensive care unit. Am J Crit Care. 2006;15(5):502-509.

5. Almashrafi A, Alsabti H, Mukaddirov M, Balan B, Aylin P. Factors associated with prolonged length of stay following cardiac surgery in a major referral hospital in Oman: a retrospective observational study. BMJ Open. 2016;6(6):e010764.

6. Almashrafi A, Elmontsri M, Aylin P. Systematic review of factors influencing length of stay in ICU after adult cardiac surgery. BMC Health Serv Res. 2016;16:318.

7. Tribuddharat S, Sathitkarnmanee T, Ngamsangsirisup K, et al. Development of an open-heart intraoperative risk scoring model for predicting a prolonged intensive care unit stay. Biomed Res Int. 2014;2014: 158051.
8. Nashef SA, Roques F, Michel P, Gauducheau E, Lemeshow S, Salamon R. European system for cardiac operative risk evaluation (EuroSCORE). Eur J Cardiothorac Surg. 1999;16(1):9-13.

9. Roques F, Nashef SA, Michel P, et al. Risk factors and outcome in European cardiac surgery: analysis of the EuroSCORE multinational database of 19030 patients. Eur J Cardiothorac Surg. 1999;15(6):816822; discussion 822-823.

10. Messaoudi N, De Cocker J, Stockman BA, Bossaert LL, Rodrigus IE. Is EuroSCORE useful in the prediction of extended intensive care unit stay after cardiac surgery? Eur J Cardiothorac Surg. 2009;36(1):35-39.

\section{Publish your work in this journal}

Therapeutics and Clinical Risk Management is an international, peerreviewed journal of clinical therapeutics and risk management, focusing on concise rapid reporting of clinical studies in all therapeutic areas, outcomes, safety, and programs for the effective, safe, and sustained use of medicines. This journal is indexed on PubMed Central, CAS,
EMBase, Scopus and the Elsevier Bibliographic databases. The manuscript management system is completely online and includes a very quick and fair peer-review system, which is all easy to use. Visit http://www.dovepress.com/testimonials.php to read real quotes from published authors.

Submit your manuscript here: http://www.dovepress.com/therapeutics-and-clinical-risk-management-journal 